\title{
Vivências quotidianas na rua: os costumes e foros na Idade Média portuguesa
}

\author{
Lifestyles in the street: the Customs and Laws in the Portuguese Middle Age
}

Maria Alice da Silveira Tavares*

\section{Resumo}

Neste trabalho, pretendemos analisar as ruas e as vivências quotidianas nos concelhos medievais portugueses (Alfaiates, Castelo Bom, Castelo Melhor, Castelo Rodrigo, Guarda, Santarém, Torres Novas, Évora e Beja), tendo como suporte os seus costumes e foros redigidos no século XIII. Utilizamos exclusivamente esta fonte jurídica de caráter local e consuetudinário porque nos oferece múltiplos campos de análise para o estudo das estruturas urbanas, tais como a rua, da sociedade municipal medieval e dos seus modos de vida. Para levar a cabo o nosso estudo, estabelecemos três pontos de análise diferentes, assentes na criminalidade urbana, fazendo uma apresentação dos delitos e conflitos, bem como das penas estipuladas. Em segundo lugar, refletiremos sobre as condições higiene e salubridade e, por fim, focaremos a atenção na economia desenvolvida, sobretudo pelos mesteirais e comerciantes nas ruas.

Palavras-chave: Portugal; Costumes e Foros; Século XIII; Idade Média; Ruas.

\begin{abstract}
The aim of this study is to provide an analysis the streets and lifestyles in Portuguese town councils (Alfaiates, Castelo Rodrigo, Castelo Melhor, Castelo Bom, Guarda, Santarém, Torres Novas, Évora e Beja), in the Middle Ages, based on their customs and laws elaborated in the 13th century. We use this legal source of local character and customary exclusively as it offers multiple fields of analysis to study of urban structures, such as the street, the medieval municipal society and yours lifestyles. To carry out our study, we established three points of different analysis, based on urban crime, making a presentation of crimes and conflicts, as well as stipulated penalties. Second, we reflect on the conditions of hygiene and health and, finally, we will focus attention on developed economy, especially by artisans and traders in the streets.
\end{abstract}

Keywords: Portugal; Customs and Law; $13^{\text {th }}$ century; Middle Ages; Streets.

\footnotetext{
* Doutora em História Medieval pela Universidade de Lisboa - Portugal. Professora do Instituto de Estudos Medievais da Universidade Nova de Lisboa, Portugal. Cátedra de Estudos Sefarditas Alberto Benveniste da Universidade de Lisboa, Portugal.
} 


\section{Introdução}

O presente texto tem como objetivo dar a conhecer as vivências quotidianas de rua das populações das cidades portuguesas, na Idade Média, da região de Riba-Côa (Alfaiates, Castelo Bom, Castelo Melhor e Castelo Rodrigo), Guarda, Torres Novas, Santarém, Évora e Beja, ao longo do século XIII, com base numa única fonte jurídica de caráter municipal: os costumes e foros. Para levar a cabo o nosso estudo, definimos três pontos de análise diferentes, assentes na criminalidade urbana, na salubridade e na economia desenvolvida nas ruas, uma vez que podemos abordar esta temática sob múltiplos pontos de vista. Pretendemos, deste modo, facilitar o tratamento dos conteúdos das normativas costumeiras, assim como percecionar melhor os modos de vida diários nas ruas dos concelhos medievais portugueses. Em primeiro lugar, faremos um breve balanço da criminalidade urbana que costumava ocorrer nas artérias das cidades, procedendo, à apresentação dos delitos e dos conflitos, bem como das suas respetivas molduras penais, dos mecanismos de controle e de prevenção a ter linha de conta pelos habitantes dos concelhos. Num segundo momento, debruçar-nos-emos sobre os problemas de higiene e de salubridade, que afetavam as cidades e as soluções encontradas pelas autoridades camarárias, com o intuito de incutir modelos de conduta e de bem-estar às populações. Por fim, centrar-nos-emos na rua, como um espaço público importante para o desenvolvimento de atividades económicas, principalmente mesteiral e comercial. Estes setores são, contudo, motivo de conflitos nos concelhos, visto que costumavam causar prejuízos às populações, como podemos inferir através das fontes objeto de análise.

Esta temática sobre as ruas e os modos de vida das populações nos centros urbanos, em Portugal, tem sido alvo de atenção nas últimas décadas. Isso tem ocorrido em função do desenvolvimento de estudos sobre a história urbana, com o objetivo de analisar as cidades, sobretudo, numa perspetiva urbanística, de organização do espaço físico e da sociedade. (SILVA, 1994, p. 121-134; BEIRANTE, 1995, p. 10; GONÇALVES, 1996, p. 77-95). No entanto, não deixa de ser parca a bibliografia sobre as vivências de rua das gentes dos concelhos, principalmente, a partir de fontes de natureza jurídica, tais como os costumes e foros, as posturas, as atas de vereações e entre outras. Em Espanha, estas problemáticas são, porém, recorrentes numa ótica transdisciplinar, podendo contar com vários contributos nas áreas da história, do direito e da história urbana. (LADERO QUESADA, 1998, p. 111-128; BUENO 
DOMÍNGUEZ, 2015, p. 39-58; BONACHÍA HERNANDO, 2013, p. 91-117). Neste sentido, serão objeto de trabalho os costumes e foros da região de Riba-Côa - Alfaiates (1209-1229), Castelo Bom (1237), Castelo Rodrigo (1211-1237) e Castelo Melhor (1237) -, atuais povoados portugueses, após a celebração do Tratado de Alcanices, em 1297, que definiu mais um passo na construção da fronteira luso-castelhana, ao passo que Cáceres, Coria, Usagre e Salvaleón permaneceram no Reino de Leão e Castela, localizadas atualmente na Região Autónoma da Extremadura. A esta análise, incluiremos ainda os costumes e foros de outras cidades portuguesas, tais como, da Guarda, Torres Novas, Santarém, Beja e Évora. Esta última cidade constitui um caso particular, porque os seus códigos costumeiros encontram-se atualmente desaparecidos. Partindo deste pressuposto, usaremos os regulamentos municipais transmitidos aos povoados de Terena (1280), Alcáçovas (1299); Portel (1299), segundo José Domingues (2015, p. 156), Alcácer do Sal e Garvão (1267), permitindo-nos, deste modo, uma aproximação ao corpo costumeiro de Évora.

Os costumes e foros são assim regulamentos de caráter consuetudinário e municipal que surgem da " [...] necessidade própria e espontânea de criação de Direito por parte das sociedades que se acham entregues a si mesmas”. (SILVA, 1971, p. 218). Estas normativas foram transmitidas oralmente de geração em geração. Mais tarde, foram compiladas e registadas por escrito, de forma paulatina, talvez, a partir dos finais do século XII até aos inícios do século XIV, dando lugar a compilações, designadas de códigos. Não deixa de ser, porém, difícil definir uma datação precisa para situar as referidas normas no tempo pois, como destaca José Domingues, não há “[...] correspondência entre o momento de registo escrito que chega até nós e a sua génese" (DOMINGUES, 2015, p. 154). Este trabalho de datação levanta-nos, por outro lado, algumas dificuldades devido às escassas menções cronológicas que podemos encontrar ao longo dos costumes e foros. Podemos, assim, afirmar que o processo de redação destes códigos costumeiros abrange um período de mais de um século, provavelmente, desde o reinado de D. Sancho I (1185-1211) até à governação de D. Dinis (1279-1325). Ou seja, todas as datas que se encontram nas fontes são, portanto, relativas ao reinado dionisino. No entanto, podemos encontrar outro tipo de indicadores que nos levam a pressupor que o início da redação dos corpora costumeiros é ainda mais remoto, correspondendo a um momento anterior ao século XIII. É o que acontece quando nos deparamos com a referência ao monarca D. Sancho I (1185-1211), à sua mulher e aos seus filhos, nos regulamentos costumeiros do concelho da Guarda, levando-nos a recuar 
no tempo os momentos da passagem por escrito dos direitos consuetudinários das vilas portuguesas. Nos costumes e foros de Santarém, encontramos outro tipo de referência de natureza toponímica: o vocábulo "Guimarães", levando-nos a questionar a antiguidade e a origem das normas, uma vez que esta localidade foi Sede do Condado Portucalense. Este facto permite-nos, portanto, lançar a hipótese de estarmos diante de um foro muito mais antigo talvez anterior ou proveniente do período condal (sécs. XIXII).

Já os costumes e foros de Riba-Côa obedecem, porém, a uma cronologia diferente, respeitante aos reinados do rei de Leão, D. Afonso IX (1171-1230) e D. Fernando III (1201-1252) de Leão e Castela. Estes regulamentos foram outorgados por iniciativa régia, com o objetivo de promover e desenvolver o povoamento de espaços pouco apelativos e carentes de efetivos populacionais, num contexto de reconquista e de definição de fronteiras com o reino português.

Os corpora costumeiros podiam ainda ser comunicados a outras localidades, de forma parcial ou na sua totalidade, podendo ser introduzidas modificações nos referidos códigos, segundo as vontades das populações, dando assim lugar à formação de famílias de foros extensos, de acordo com Lindley Cintra (1984, p. 77-78). Dispomos, portanto, de alguns exemplos, como o caso de Santarém. Este concelho comunicou as suas normativas costumeiras às vilas de Borba, Oriola e Vila Nova do Alvito (atual Baronia), localizadas no Alentejo. Em Riba-Côa, assistimos também a este fenómeno. Castelo Rodrigo cedeu os seus costumes e foros à vila de Reigada, ao passo que Castelo Melhor transmitiu os referidos regulamentos ao concelho de Almendra. Este processo de formação e de divulgação dos corpora costumeiros se deve também aos pedidos efetuados pelas comunidades receptoras que demonstraram interesse em adotar as normativas de outras localidades, pedindo-lhes que lhos comunicassem. Ao analisarmos as normativas concelhias, podemos também concluir que este fenómeno se deve em parte às iniciativas régias de afirmação e de organização do reino, em especial, do monarca do D. Dinis, em detrimento da legislação consuetudinária.

Os costumes e foros são fontes jurídicas de natureza local, primordiais no estudo das cidades, oferecendo-nos múltiplos campos de investigação, entre as quais, as ruas, objetos de análise no presente texto. Dito de outra forma, os códigos costumeiros permitem-nos conhecer a organização administrativa, jurídica, económica e social dos concelhos, pois funcionavam como uma espécie de espelho dos comportamentos das comunidades municipais, isto é, como um "[...] produto e agente da vida social" 
(SILVA, 1962, p. 49). Contemplam, portanto, todos os aspectos da vida pública e privada dos indivíduos ${ }^{1}$, possibilitando-nos uma maior aproximação da realidade quotidiana e dos modos de vida das populações. É através deles que temos, por um lado, a possibilidade de entender os problemas com que as populações se deparavam e as suas respetivas soluções. Por outro lado, conseguimos conhecer as normas, os modelos de conduta e as "[...] diversas maneiras de agir consolidadas pelo uso" (PAIS, 2002, p. 132), destinadas às gentes dos concelhos, alterando e moldando os seus comportamentos, mediante um sistema coercivo e de controlo social. Estes instrumentos jurídicos são, deste modo, importantes para o estudo das ruas e das vivências das populações das comunidades urbanas, uma vez que estas fontes resultam de um trabalho constante de recomposição, reelaboração e reajustamento dos comportamentos e dos modos de vida populacionais dos concelhos portugueses e dos interesses políticoadministrativos régios.

Neste sentido, os costumes e foros demonstram claramente que as ruas foram espaços públicos de excelência no desenvolvimento da vida quotidiana das populações nos concelhos. Segundo Ladero Quesada (1998, p. 115), estamos diante de espaços de sociabilidade, de conflitualidade e de circulação de transeuntes, mercadorias e animais, mas também de preocupação por parte das autoridades locais, com os objetivos de regular as suas utilizações, garantindo, assim, a segurança, o bem-estar das populações e dos seus bens e o desenvolvimento das atividades económicas. Vejamos, então, de que forma isso ocorria.

\section{A rua: criminalidade e violência}

A convivência diária nas ruas dos concelhos portugueses nem sempre foi pacífica. A partir dos seus costumes e foros, podemos depreender facilmente um semfim de conflitos, de crimes e de diversas formas de violência urbana, bem como um conjunto de disposições penais. Tendo em vista a melhor compreensão da criminalidade

\footnotetext{
${ }^{1}$ Por ámbito privado, entendam-se todos os aspetos relacionados com a vida e a casa particular dos indivíduos. Por público, podemos compreender todas as vivências das pessoas em espaços públicos, tais como as ruas, que se encontram sob a tutela do concelho. Veja-se: LADERO QUESADA, ManuelFernando. La vivienda. Espacio público y espacio privado en el paisaje urbano medieval. In: IGLEISA DUARTE, José Ignacio de la (Org.). En La vida cotidiana en la Edad Media. VIII Semana de Estudios Medievales. Nájera: Instituto de Estudios Riojanos, 1998, p. 113. Disponível em: <https://dialnet.unirioja.es/servlet/articulo?codigo=563903>. Acesso em: 28 maio 2012, BUENO DOMíngUEZ, María Luísa. Contactos con la vida material en Zamora. Siglos XII-XV. In: Espacio, Tiempo y Forma. Serie III, H $^{\mathbf{a}}$ Medieval, Madrid, v. 18, p. 45, 2015.
} 
urbana, procedemos, por questões metodológicas, ao levantamento e à quantificação das normativas referentes aos delitos e às transgressões para fazermos uma análise mais minuciosa dos tipos de crime e das diversas formas de violência que eram habituais nas comunidades municipais. Sendo assim, partimos de um universo de 3446 costumes e foros, possibilitando-nos o registo de 554 normativas sobre os delitos que podiam ser levados a cabo nas ruas, entre os quais contra a integridade física, a honra, a propriedade e entre outros.

Diante deste cenário, começamos o nosso estudo com os crimes contra a vida dos indivíduos. Notamos, portanto, que os delitos de agressão física constituíam a maioria dos casos, representando um 39\% das normativas objeto de análise. Este facto põe-nos em evidência que este tipo de criminalidade era bastante frequente nos concelhos medievais portugueses.

Se observarmos os seus "corpora" costumeiros com mais detalhe, apercebemonos que nem todos os atos de violência física tinham a mesma importância, levando assim as autoridades judiciais a definirem uma série de molduras penais para cada caso. Atendamos aos exemplos das vilas de Riba-Côa. Os ferimentos causados a outrem, incluindo cortar as orelhas e partir os dentes ou os dedos, eram geralmente atos punidos com o pagamento de coimas. Já os ferimentos cometidos em determinadas partes do corpo, tais como no rostro (olhos e nariz), nos membros superiores e inferiores; nos seios e nos órgãos sexuais masculinos ${ }^{2}$ tinham, contudo, um caráter particular, uma vez que eram considerados agravados, sendo equiparados a homicídios. Este facto depreende-se com as consequências que este tipo de ferimentos costumava acarretar, como, por exemplo, o derrame de sangue em abundância. Além disso, acrescentamos que as sequelas físicas poderiam provocar na "[...] cara o en otro lugar claramente visible del cuerpo, y sea esa señal constituía en la época una injuria además de un delito". (CÓRDOBA DE LA LLAVE, 2005, p. 332). Por outro lado, convém frisar que tais feridas implicavam problemas físicos nas pessoas, impedindo-as de levar a cabo as suas atividades diárias.

As agressões físicas cometidas contra qualquer pessoa, independentemente do seu estatuto sociojurídico, sem esquecer os dependentes e os cativos muçulmanos eram factor de preocupação, punindo-as com coimas que revertiam a favor dos amos ou dos donos dos escravos. Estas funcionavam, contudo, como uma espécie de indemnização

\footnotetext{
${ }^{2}$ Note-se que nos regulamentos costumeiros não se faz menção aos órgãos sexuais femininos. Neste sentido, não se prevê qualquer tipo de penalização.
} 
pelos danos e prejuízos causados, colocando as vítimas numa posição de desvantagem, devido às suas relações étnicas, sociais e jurídico-laborais.

Os regulamentos costumeiros dão-nos conta de outros detalhes das agressões corporais, embora nos seja difícil deslindar as motivações e as diversas formas como este tipo de delito podia ser cometido. Dispomos de algumas indicações relativas aos artefactos utilizados (objetos de arremesso, paus, cutelos pedras, fustes, por exemplo) para investir contra qualquer um, que eram também alvo de consideração da parte das autoridades judiciais na aplicação da justiça.

Ainda dentro desta categoria de crimes, seguem-se os homicídios que correspondiam a 16,6\%. Ao procedermos à sua análise, encontramos, porém, estipulada outro tipo de penalização nos concelhos ribacoanos e da Guarda: o "omizio", a inimizade da família da vítima, utilizada normalmente para complementar as sanções monetárias. Esta pena consistia na expulsão do autor do crime do concelho, que ficava desprotegido e à mercê da vingança privada da parte do círculo familiar da vítima, abrangendo todos os parentes até o terceiro grau ${ }^{3}$. Ou seja, o homicida era desterrado dos concelhos, ficando "[...] expuesto a la venganza de la parte ofendida, que impunemente podia matarle". (HINOJOSA, 1915, p. 83), até que os parentes da vítima lhe concedessem o perdão. Durante esta fase, era proibido amparar o agressor nas casas, nas cidades ou nas aldeias, uma vez que não só era inimigo dos familiares do morto, mas também da comunidade. Quem o fizesse era considerado, de certa forma, cúmplice por dar guarida a alguém que cometeu um delito de sangue contra a vida de uma pessoa, sujeitando-se também ao pagamento de uma multa.

Não obstante, quando nos debruçamos sobre os costumes e foros de Beja, apercebemo-nos de um outro cenário associado à vingança privada - a chamada reconciliação -, permitindo o criminoso regressar ao seu concelho e ser reintegrado na sociedade. O retorno do antigo homicida era marcado por uma espécie de ritual de natureza protocolar, o "osculum pacis”, que não só garantia a paz entre as duas famílias, mas também o seu retorno ao município. Para os devidos efeitos, devia-se convocar uma reunião concelhia e contar também com a presença de algum parente mais próximo da vítima, em representação da família. Em última análise, a rúbrica número 135 dos "corpora" costumeiros de Beja oferece uma descrição deste procedimento, indicando-

\footnotetext{
${ }^{3}$ Este procedimiento penal, "Al estado de enemistad entre la parte ofendida y el sometido al derecho de venganza, se llamaba «inimicitia»". HINOJOSA, Eduardo. El Elemento Germánico en el Derecho Español, Madrid: Junta para ampliación de Estudios e investigaciones científicas. Centro de Estudios Históricos, 1915, p. 32.
} 
nos com mais detalhe que "aquele que cometesse homicídio deverá ficar de joelhos e meter o seu cutelo na mão do queixoso, enquanto o primeiro lhe deve pegar na mão, alçá-lo e beijá-lo na boca diante dos homens bons para ficarem amigos" ${ }^{\text {. }}$. Pondo de outro modo, este procedimento judicial permitia, acima de tudo, reestabelecer a paz, convertendo a "enemistad en amistad" (HINOJOSA, 1915, p. 65).

Passemos a análise dos delitos contra a liberdade e a autodeterminação sexual, tais como as violações e a prática de lenocídio, que constituíam um problema para as autoridades municipais, pois colocavam em causa a honra e a boa fama da mulher, do homem e da sua família. (CÓRDOBA DE LA LLAVE, 2008, p. 202). Neste sentido, as violações representam 9,2\% das normas e os comportamentos de lenocídio ocupam $0,72 \%$. Os concelhos determinaram, desta forma, um conjunto de penas que costumavam variar em função da importância e do estatuto municipal e "civil" das vítimas. Vejamos, com mais detalhe, os exemplos dos concelhos ribacoanos. Sendo assim, podemos afirmar que as penas eram mais severas para as violações que ocorressem contra as mulheres casadas, devendo o agressor ser condenado à morte, por enforcamento $^{5}$, enquanto nos restantes casos, se procedia à aplicação de coimas.

Nos concelhos de Riba-Côa, assim como Santarém e Beja, constatamos uma série de normativas que refletem o cuidado da parte das autoridades locais em afixar padrões comportamentais e mecanismos de prova, estipulados precisamente para as demandas de violação. Estas tinham o objetivo de dar sustentabilidade e credibilidade às vítimas em tribunal, uma vez que se trata de um delito difícil de provar e, em muitos casos, resultava inconclusivo. Por exemplo, nas vilas ribacoanas, as vítimas deviam apresentar-se "rasgadas e corrompidas" diante dos alcaldes e dos homens bons, para

\footnotetext{
4 "fiir o omezio aquel que hade correger ficar os geolhos e meter o seu cuytelo en maão daquel que ha del queixume e o outro o deue fillar pela maão e alçalo e beyialo na boca perdante homeens boons e per ali ficarem amigos.", CFB", Portvgaliae Monumenta Historica. Leges et Consuetudines. vol. II. Olisipone: IUSSU Academiae Seicentiarum Olisiponensis, MDCCCLVI, 1856, p. 64, Tít. [135].

5 "CFCM", Portvgaliae Monumenta Historica. Leges et Consuetudines. vol. I. Olisipone: IUSSU Academiae Seicentiarum Olisiponensis, MDCCCLVI, 1856, p. 906, Tít. [86], Lv. III; "CFCB", Portvgaliae Monumenta Historica. Leges et Consuetudines. vol. I. Olisipone: IUSSU Academiae Seicentiarum Olisponensis, MDCCCLVI, 1856, p. 750, Tít. [52]; "CFCR", Portvgaliae Monumenta Historica. Leges et Consuetudines. vol. I. Olisipone: IUSSU Academiae Seicentiarum Olisiponensis, MDCCCLVI, 1856, p. 860, Tít. [95], Lv. III; “CFA”, Portvgaliae Monumenta Historica. Leges et Consuetudines. vol. I. Olisipone: IUSSU Academiae Seicentiarum Olisiponensis, MDCCCLVI, p. 795, Tít. [38].
} 
fazerem prova dos seus sinais de violência ${ }^{6}$. Além disso, devia-se proceder de forma semelhante em Santarém e Beja, devendo as mulheres aparecer na justiça a bradar, a chorar e a acusar o criminoso em público ${ }^{7}$.

Não obstante, nem todos os crimes de natureza sexual eram tipicamente femininos, tratando-se de uma questão de gênero, como acontecia com as violações. A alcoviteirice era levada a cabo quer por mulheres, quer por homens, encontrando-se somente estipulada nos preceitos ribacoanos. Em ambos os casos, se procedia à punição com a pena capital ${ }^{8}$, se bem que aos homens lhes estava reservada a morte na forca, ao passo que as mulheres eram queimadas nas fogueiras ${ }^{9}$.

Já os delitos contra a liberdade pessoal, as ameaças, com ou sem armas, e a honra (injúrias) representam um 10,5\%. Os primeiros podiam estar na origem de outros problemas que se encontram enunciados nos códices costumeiros, tais como as agressões físicas e os homicídios. Diante deste panorama, podemos ainda acrescentar a posse e a ostentação de armas, como as facas, na via pública, pois semeavam o medo

\footnotetext{
6 "CFCM", Portvgaliae Monumenta Historica. Leges et Consuetudines. vol. I. Olisipone: IUSSU Academiae Seicentiarum Olisiponensis, MDCCCLVI, 1856, p. 906, Tít. [86], Lv. III; "CFCB", Portvgaliae Monumenta Historica. Leges et Consuetudines. vol. I. Olisipone: IUSSU Academiae Seicentiarum Olisiponensis, MDCCCLVI, 1856, p. 750, Tít. [52]; "CFCR", Portvgaliae Monumenta Historica. Leges et Consuetudines. vol. I. Olisipone: IUSSU Academiae Seicentiarum Olisiponensis, MDCCCLVI, 1856, p. 860, Tít. [95], Lv. III; "CFA", Portvgaliae Monumenta Historica. Leges et Consuetudines. vol. I. Olisipone: IUSSU Academiae Seicentiarum Olisiponensis, MDCCCLVI, 1856, p. 795, Tít. [38].

7 "CFS", Portvgaliae Monumenta Historica. Leges et Consuetudines. vol. II. Olisipone: IUSSU Academiae Seicentiarum Olisiponensis, MDCCCLVI, 1856, p. 21, Tít. [39]; "CFS", BRANDÃO, Zeferino. Monumentos e Lendas de Santarém. Lisboa: David Corazzi - Editor, 1883, p. 372, Tít. [57]; "CFBb", RODRIGUES, Maria Celeste Matias. Dos Costumes de Santarém. 1992. (Mestrado em Linguística Portuguesa Histórica - A Faculdade de Letras da Universidade de Lisboa, Lisboa, 1992, p. 119, Tít. [39]; "CFB", Portvgaliae Monumenta Historica. Leges et Consuetudines. vol. II. Olisipone: IUSSU Academiae Seicentiarum Olisiponensis, MDCCCLVI, 1856, p. 63, Tít. [121]; "CSCVNA", Portvgaliae Monumenta Historica. Leges et Consuetudines. vol. II. Olisipone: IUSSU Academiae Seicentiarum Olisiponensis, MDCCCLVI, 1856, p. 47- 48, Tít. [38].

8 "CFCM", Portvgaliae Monumenta Historica. Leges et Consuetudines. vol. I. Olisipone: IUSSU Academiae Seicentiarum Olisiponensis, MDCCCLVI, 1856, p. 908, Tít. [105], Lv. IV; "CFCB", Portvgaliae Monumenta Historica. Leges et Consuetudines. vol. I. Olisipone: IUSSU Academiae Seicentiarum Olisiponensis, MDCCCLVI, 1856, p. 787, Tít. [385]; “CFCR”, Portvgaliae Monumenta Historica. Leges et Consuetudines. vol. I. Olisipone: IUSSU Academiae Seicentiarum Olisiponensis, MDCCCLVI, 1856, p. 862, Tít. [113], Lv. III; "CFA", Portvgaliae Monumenta Historica. Leges et Consuetudines. vol. I. Olisipone: IUSSU Academiae Seicentiarum Olisiponensis, MDCCCLVI, 1856, p. 841, Tít. [478].

${ }^{9}$ Possivelmente, esta realidade se deva ao facto de as sentenças por enforcamento ou decapitação implicarem a exposição do corpo da mulher "sin vida en el patíbulo, picota o rollo, y socialmente se consideraba indecoroso y denigrante el espectáculo de la exposición de una mujer de esta forma". (BAZÁN DÍAZ, 2008, p. 219). No entanto, depreender que haveria uma certa igualdade entre homens e mulheres, sobretudo no âmbito, processual e penal.
} 
dos transeuntes, criando assim um clima de insegurança e desconfiança pouco propício nos concelhos, como podemos intuir, a partir das normativas costumeiras.

Quanto às injúrias verbais, estas afetavam a dignidade e a boa conduta das pessoas. Ao observarmos os corpora costumeiros dos concelhos medievais portugueses selecionados, podemos fazer um levantamento de uma série de insultos, referentes não só a condutas sexuais, religiosas e físicas, mas também ao estado de saúde das pessoas, como acontecia com os leprosos. A lepra era uma doença que costumava acarretar a segregação social (MONTERDE GARCÍA, 2002, p. 699). As injúrias mais comuns com que nos deparamos eram as seguintes: gafo, cornudo, traidor, fudidunculo (sodomita) e entre outras. Atendamos a alguns exemplos. Os judeus e os muçulmanos de Santarém e de Beja, convertidos ao cristianismo, constituíam um caso particular, sobretudo do ponto de vista religioso, pois eram facilmente apelidados de tornadiços (cristãosnovos), fazendo-lhes lembrar as suas origens étnico-religiosas. Este tipo de agressão verbal gerava facilmente conflitos entre os cristãos-velhos e os membros das comunidades, muçulmana e judaica, colocando os tornadiços (cristãos-novos) numa situação de fragilidade no quotidiano municipal português. Ainda na mesma linha de pensamento, o mesmo devia acontecer nas vilas de Riba-Côa, visto que, a propósito dos indivíduos rotulados de "judeus", pois esta injúria evocava igualmente a condição religiosa de uma comunidade considerada minoritária e que gozava de um estatuto sociojurídico especial no seio da sociedade.

Em terceiro lugar, chamamos a atenção para os crimes contra o património em geral, que correspondem a um 7\% das normas costumeiras. Nesta categoria, consideramos o registo de normativas que dizem respeito a furtos, a roubos, a usurpações e a danos causados nos animais nos concelhos portugueses, em ambiente urbano. Normalmente, os animais, como, por exemplo, os cães, costumavam ser alvo de maus tratos, vindo, em muitos casos, a morrer, como podemos notar nos costumes e foros ribacoanos ${ }^{10}$.

\footnotetext{
10 "CFCM", Portvgaliae Monumenta Historica. Leges et Consuetudines. vol. I. Olisipone: IUSSU Academiae Seicentiarum Olisiponensis, MDCCCLVI, 1856, p. 931, Tit. [309], Lv.V III; "CFCR", Portvgaliae Monumenta Historica. Leges et Consuetudines. vol. I. Olisipone: IUSSU Academiae Seicentiarum Olisiponensis, MDCCCLVI, 1856, p. 888, Tít. [323], Lv. VIII; "CFCB", Portvgaliae Monumenta Historica. Leges et Consuetudines. vol. I. Olisipone: IUSSU Academiae Seicentiarum Olisiponensis, MDCCCLVI, 1856, p. 776, Tít. [277]; "CFA", Portvgaliae Monumenta Historica. Leges et Consuetudines. vol. I. Olisipone: IUSSU Academiae Seicentiarum Olisiponensis, MDCCCLVI, 1856, p. 821, Tít.277.
} 
Os "delitos económicos"11 constituíam outro problema para as autoridades judiciais dos concelhos portugueses, como verificamos nos costumes e foros. Apesar dos riscos que o uso desta categoria acarreta aplicado à realidade medieva, uma vez que se trata de uma realidade atual, levando-nos a cair facilmente em situações de anacronismo, podemos afirmar que as populações mediévicas tinham uma clara noção da existência de crimes e de más práticas que costumavam ocorrer no desenvolvimento das atividades económicas, chegando a ser sancionadas nos seus ordenamentos costumeiros. Ora, vejamos, as infrações contra a qualidade e a composição dos bens e géneros alimentares, o açambarcamento e a especulação ocupam um $7 \%$ das normativas. Se fizermos uma simples leitura dos corpora selecionados, deparamo-nos que nem sempre a produção de produtos e o comércio eram levadas a cabo nas melhores condições, visto que estavam na origem de uma série de conflitos e de dificuldades que impediam a circulação e o abastecimento de bens às populações urbanas, em detrimento dos consumidores, aportando-lhes prejuízos patrimoniais e prejudicando o desenvolvimento da economia local (BERNAL PEÑA, 2011, p. 75). Centremo-nos, assim, no caso das padeiras, uma vez que eram mesteirais e comerciantes. Estas tinham o hábito de fabricar e vender os pães crus e em más condições a preços normalmente elevados como se fossem mercadorias de qualidade, apropriadas para o consumo das populações ${ }^{12}$. As padeiras, assim como outros profissionais, costumavam partir de ardis para tirar proveito das necessidades das pessoas, com o objetivo de satisfazer os seus interesses económicos, procurando o enriquecimento fácil e ilegítimo, como acontecia também com os regateiros (agentes intermediários), que iremos aprofundar mais adiante. Neste sentido, todos aqueles que burlassem ou especulassem, eram alvo de penalizações pecuniárias, embora não fosse comum aplicar as referidas sanções de forma isolada. Por exemplo, proibia-se os mesteirais de exercerem as suas profissões

\footnotetext{
${ }^{11}$ Compreendem todas as atividades delituosas contra a economia, entre as quais destacamos as infrações contra a qualidade e a composição dos bens e gêneros alimentares; o crime e açambarcamento, a especulação, etc. Embora estejamos diante de um conceito contemporâneo e anacrónico, os costumes e foros deixam transparecer uma clara consciência e preocupação da parte das comunidades locais medievas em regulamentar e combater as transgressões e os crimes contras as atividades económicas e o seu devido funcionamento, zelando pela correta organização socioeconómica municipal.
}

12 "CFCM", Portvgaliae Monumenta Historica. Leges et Consuetudines. vol. I. Olisipone: IUSSU Academiae Seicentiarum Olisiponensis, MDCCCLVI, 1856, p. 925, Tít. [249], Lv.VI; "CFCR", Portvgaliae Monumenta Historica. Leges et Consuetudines. vol. I. Olisipone: IUSSU Academiae Seicentiarum Olisiponensis, MDCCCLVI, 1856, p. 881, Tít. [262], Lv. VI; "CFA", Portvgaliae Monumenta Historica. Leges et Consuetudines. vol. I. Olisipone: IUSSU Academiae Seicentiarum Olisiponensis, MDCCCLVI, 1856, p. 808, Tít. [157]; "CFCB", Portvgaliae Monumenta Historica. Leges et Consuetudines. vol. I. Olisipone: IUSSU Academiae Seicentiarum Olisiponensis, MDCCCLVI, 1856, p. 763, Tít. [157]. 
durante o ano vigente, com a finalidade de os lesar, aportando-lhes prejuízos materiais e económicos.

Por último, acrescentamos uma categoria diferente, que lhe iremos chamar "outros crimes", com os objetivos de inserir e analisar outro tipo de comportamentos e condutas quotidianas que eram também prejudiciais para o bem-estar das populações concelhias. Partindo deste pressuposto, consideramos os delitos contra a sociedade, isto é, os de perigo comum, que representam $3,42 \%$ das normativas. Ressaltamos, desta forma, o ato de deitar lixos ou outras substâncias nas áreas públicas; a construção desenfreada de casas ou de "indústrias"13 e de infraestruturas que podiam ser perigosas para as populações urbanas, que veremos nos itens seguintes.

Posto isto, podemos concluir que os delitos e a violência nas ruas eram transversais a todos os grupos sociais, profissionais e étnico-religiosos. Os cavaleiros, os peões, os amos, os dependentes e as minorias, os judeus e os muçulmanos, podiam ser autores e vítimas de crimes ${ }^{14}$. Dito de outra forma, as práticas delituosas e de outras transgressões não eram uma questão social ou de género, embora chamemos a atenção para a existência de crimes de foro sexual, tipicamente femininos, tais como a violação, pois as mulheres eram somente as vítimas. Neste caso, a diferença de género não deixa de ser pertinente, uma vez que estamos diante de crimes com consequências penais específicas para os criminosos, tendo também como factor de ponderação a condição das vítimas, e de normativas com caraterísticas próprias, nas quais se encontram definidos os procedimentos que as vítimas deveriam adotar em sua defesa.

Vejamos as penas. A partir dos regulamentos costumeiros, podemos encontrar diversas penalizações. Entre elas destacamos as penas pecuniárias (as mais comuns e que constituíam normalmente uma fonte de rendimento dos municípios); o confisco de bens, os castigos físicos (amputar membros e cortar as mãos, por exemplo) e as penas de morte, na fogueira ou na forca. Nos delitos de homicídio, encontramos, porém, estipulada outro tipo de penalização: a inimizade da família da vítima, complementando as sanções monetárias. Ser inimigo, como já nos referimos, acarretava não só o desterro do criminoso, tendo por consequência a sua expulsão das vilas, mas também ficava sujeito à vingança privada (à morte) da parte dos parentes da vítima, nas palavras de Orlandis (1947, p. 77). O objetivo desta penalização consistia em restaurar a paz e

\footnotetext{
${ }^{13}$ Por "indústrias" entendam-se os mesteres ou as atividades artesanais.

${ }^{14}$ Independentemente do estatuto jurídico, social e étnico-religioso, qualquer indivíduo podia comparecer em juízo e ser alvo de penalizações, em função do delito ou da transgressão que cometesse, segundo as disposições estipuladas nos regulamentos costumeiros.
} 
reparar a justiça que ficou comprometida com a prática de crimes como os homicídios, as agressões físicas e as violações. A privação da liberdade era uma outra alternativa que vemos mencionada nas normativas costumeiras, constituindo uma pena preventiva e, em algumas circunstâncias funcionava como subsidiária (SAINZ GUERRA, 2006, p. 560). Assim, os presos de Riba-Côa deviam, por exemplo, permanecer no cepo durante um determinado período de tempo (oito dias ou mais) ${ }^{15}$.

A aplicação das molduras penais variava consoante o tipo de delito. Ao analisarmos os costumes e foros, podemos concluir que eram tidos em linha de conta uma série de fatores para formular as sentenças. Ou seja, os delitos eram julgados em função da natureza, da gravidade, dos sujeitos ativo ou passivo (pessoas, animais, por exemplo), da tipologia do crime, do local, da hora do dia - dia ou de noite -, das motivações, da condição sociojurídica da vítima e do agressor; o uso ou não de armas, as circunstâncias da responsabilidade penal (a legítima defesa) e entre outros parâmetros.

Por outro lado, foi possível encontrar normativas que refletem uma preocupação pela prevenção do crime. As autoridades municipais tiveram, assim, o cuidado de reprimir comportamentos que pudessem estar na origem de condutas delituosas, com o fim de as pessoas adotarem atitudes e modos de vida quotidianos, considerados adequados e de boa conduta para o bem-estar de todos. Partindo deste pressuposto, cabe-nos refletir sobre os conteúdos das mesmas e como os concelhos puseram em marcha algumas medidas. Vejamos os seguintes exemplos. Andar de noite, nos concelhos ribacoanos, sem qualquer motivo aparente era suscetível a desconfianças e receios da parte das populações e das autoridades municipais. Neste sentido, a escuridão era encarada como propícia para a prática de delitos e infrações, pois os delinquentes não podiam ser facilmente reconhecidos. Além disso, sublinhamos que esta fase do dia era entendida como uma agravante na avaliação das demandas em tribunal. Ora, todos aqueles, que fossem apanhados a circular de noite e se recusassem a dizer de onde e a que vinham, podiam ser considerados ladrões, ficando sujeitos a ser penalizados como

15 "CFCB", Portvgaliae Monumenta Historica. Leges et Consuetudines. vol. I. Olisipone: IUSSU Academiae Seicentiarum Olisiponensis, MDCCCLVI, 1856, p. 782, Tít. [331]; "CFA”, Portvgaliae Monumenta Historica. Leges et Consuetudines. vol. I. Olisipone: IUSSU Academiae Seicentiarum Olisiponensis, MDCCCLVI, 1856, p. 828, Tít. [334]; “CFCM”, Portvgaliae Monumenta Historica. Leges et Consuetudines. vol. I. Olisipone: IUSSU Academiae Seicentiarum Olisiponensis, MDCCCLVI, 1856, p. 938, Tít. [367], Lv. VIII; CFCR”, Portvgaliae Monumenta Historica. Leges et Consuetudines. vol. I. Olisipone: IUSSU Academiae Seicentiarum Olisiponensis, MDCCCLVI, 1856, p. 895, Tít. [381], Lv. III. 
se tivessem cometido algum crime de roubo ou de furto ${ }^{16}$. Na vila de Beja, registamos também a indicação de uma medida de caráter semelhante que consiste no recolher obrigatório ao anoitecer, após o sino tocar três vezes ${ }^{17}$. Este facto implicava a interrupção das atividades diárias, a deslocação das pessoas para as suas casas, o encerramento das portas das cidades e as "[...] ruas desertas são de mais fácil vigilância" (FREITAS, 1998, p. 35). Podemos, portanto, pressupor que todo aquele que fosse surpreendido a circular nas ruas era considerado suspeito e colocava-se à mercê de ser apanhado.

O uso e porte de armas era mais uma inquietação para as autoridades locais, pois era vulgar circular-se armado no interior das vilas e nos arrabaldes. Estas podiam ser consideradas a origem de delitos e de condutas violentas, comprometendo a paz que se deveria fazer sentir nos centros urbanos. Daí haver a preocupação de os alcaldes registarem e de controlarem todos aqueles que transportassem armas, mesmo às escondidas, como acontecia, por exemplo, em Riba-Côa ${ }^{18}$.

O policiamento das ruas foi mais uma das medidas preventivas desenvolvidas, sobretudo durante a noite, em determinados espaços ou acontecimentos, tais como os mercados ou as feiras, que mobilizavam os habitantes dos concelhos e ainda atraíam pessoas vindas de fora, a fim de garantir a segurança dos indivíduos e dos seus bens. Os concelhos deviam dispor, desta forma, de um conjunto de funcionários capazes de exercerem as referidas tarefas, tais como os almotacés, os porteiros do concelho, entre outros, funcionando como uma espécie de "polícias" urbanos ${ }^{19}$.

\footnotetext{
16 "CFCB", Portvgaliae Monumenta Historica. Leges et Consuetudines. vol. I. Olisipone: IUSSU Academiae Seicentiarum Olisiponensis, MDCCCLVI, 1856, p. 772, Tít. [234]; "CFCR", Portvgaliae Monumenta Historica. Leges et Consuetudines. vol. I. Olisipone: IUSSU Academiae Seicentiarum Olisiponensis, MDCCCLVI, 1856, p. 896, Tít. [384], Lv. VIII; "CFCM", Portvgaliae Monumenta Historica. Leges et Consuetudines. vol. I. Olisipone: IUSSU Academiae Seicentiarum Olisiponensis, MDCCCLVI, 1856, p. 939, Tít. [370], Lv.VIII.

17 "CFB", Portvgaliae Monumenta Historica. Leges et Consuetudines. vol. II. Olisipone: IUSSU Academiae Seicentiarum Olisiponensis, MDCCCLVI, 1856, p. 71, Títs. [98] e [99].

18 "CFCB", Portvgaliae Monumenta Historica. Leges et Consuetudines. vol. I. Olisipone: IUSSU Academiae Seicentiarum Olisiponensis, MDCCCLVI, 1856, p. 771-772, Tít. [233]; "CFCM", Portvgaliae Monumenta Historica. Leges et Consuetudines. vol. I. Olisipone: IUSSU Academiae Seicentiarum Olisiponensis, MDCCCLVI, 1856, p. 938, Tít. [369], Lv. VII; "CFCR", Portvgaliae Monumenta Historica. Leges et Consuetudines. vol. I. Olisipone: IUSSU Academiae Seicentiarum Olisiponensis, MDCCCLVI, 1856, p. 895, Tít. [383], Lv.VIII.
}

19 "CFB", Portvgaliae Monumenta Historica. Leges et Consuetudines. vol. II. Olisipone: IUSSU Academiae Seicentiarum Olisiponensis, MDCCCLVI, 1856, p. 71, Tít. [97]. 


\section{A rua: higiene e salubridade}

Como já referimos anteriormente, a manutenção da higiene e da salubridade das ruas constituiu uma preocupação para as autoridades camarárias. Estes espaços públicos eram propícios a todo o tipo de sujidades e detritos resultantes não só da vida doméstica dos habitantes dos concelhos, mas também do desenvolvimento das atividades económicas, da passagem de transeuntes e de animais. Com base nestas suposições, a pergunta que se coloca é a seguinte: como os concelhos procuraram resolver estes problemas? Através dos corpora costumeiros, podemos detetar algumas medidas que visavam, sobretudo a proibição de determinados comportamentos da parte das próprias populações, com o fim de lhes incutir condições e hábitos de higiene que deveriam ser tidos em consideração, tanto a nível pessoal, como no cuidado das áreas públicas. Não obstante, nada se sabe se estas iniciativas tiveram algum impacto nas sociedades municipais mediévicas, apesar de encontrarmos normas pontuais sobre estas problemáticas urbanas. Sabemos que deitar lixo, esterco ou outras imundícies nas ruas, nas carcovas ou em outros espaços públicos eram práticas que se encontravam estipuladas nos códigos costumeiros dos concelhos, tais como Castelo Melhor ${ }^{20}$, Castelo Rodrigo $^{21}$, Castelo Bom ${ }^{22}$, Guarda ${ }^{23}$ e Torres Novas ${ }^{24}$. Todos os concelhos eram unânimes em proibir e estabelecer penas pecuniárias. A par da sujidade das vias públicas, nas normativas costumeiras das vilas ribacoanas de Castelo Rodrigo e Castelo Melhor, detetamos que catar as pulgas ${ }^{25}$ constituía um problema, devendo-se proceder de forma semelhante aos outros exemplos acabados enunciar.

A partir dos corpora costumeiros, temos também conhecimento de que as autoridades concelhias desempenharam outras iniciativas no cuidado e na preservação

20 "CFCM", Portvgaliae Monumenta Historica. Leges et Consuetudines. vol. I. Olisipone: IUSSU Academiae Seicentiarum Olisiponensis, MDCCCLVI, 1856, p. 897, Tít. [5]. Lv. I.

21 "CFCR", Portvgaliae Monumenta Historica. Leges et Consuetudines. vol. I. Olisipone: IUSSU Academiae Seicentiarum Olisiponensis, MDCCCLVI, 1856, p. 850, Tít. [6], Lv. I.

22 "CFCB", Portvgaliae Monumenta Historica. Leges et Consuetudines. vol. I. Olisipone: IUSSU Academiae Seicentiarum Olisiponensis, MDCCCLVI, 1856, p. 163, Tít. [163].

23 "CFG", Portvgaliae Monumenta Historica. Leges et Consuetudines. vol. II. Olisipone: IUSSU Academiae Seicentiarum Olisiponensis, MDCCCLVI, 1856, p. 7, Títs. [62] e [63].

24 “CFTN", Portvgaliae Monumenta Historica. Leges et Consuetudines. vol. II. Olisipone: IUSSU Academiae Seicentiarum Olisiponensis, MDCCCLVI, 1856, p. 92, Tít. [54].

25 “CFCM", Portvgaliae Monumenta Historica. Leges et Consuetudines. vol. I. Olisipone: IUSSU Academiae Seicentiarum Olisiponensis, MDCCCLVI, 1856, p, 915, Tít. [158], Lv. IV; CFCR”, Portvgaliae Monumenta Historica. Leges et Consuetudines. vol. I. Olisipone: IUSSU Academiae Seicentiarum Olisiponensis, MDCCCLVI, 1856, p. 170, [5], Lv. I. 
do aspeto das artérias das cidades. Estas não deixaram de se mostrar preocupadas, por exemplo, com a construção desenfreada e sem qualquer tipo de controlo de casas e de outras estruturas nos becos, tais como alpendres e sobrados, segundo nos elucidam os costumes e foros de Santarém. ${ }^{26}$ Com base nestas normativas, podemos, por um lado, inferir certa preocupação não só com a organização do espaço urbano, com o fim de determinar as condições para as novas construções, uma vez que estariam a crescer em altura, ao mesmo que tempo, que se alargavam na horizontal, ocupando as áreas públicas, como as ruas.

Neste sentido, enunciamos outro problema com que os concelhos de deparavam, relacionado com a localização dos mesteres e das infraestruturas consideradas "poluentes" 27 e perigosas, tais como os caleiros, os ferreiros, os ferradores, os fornos e as fráguas. Estas deviam localizar-se nos arredores das vilas; o que nem sempre aconteceria. Partindo das informações dos regulamentos locais objeto de estudo, pressupomos que os referidos mesteirais e infraestruturas eram supostamente alvo de controlo, visto que costumavam libertar fumos e outras substâncias, resultantes o uso de carvão e do fogo, propensas à proliferação de incêndios, constituindo, assim, um grave risco para as populações. Além disso, fazer fogo em plena rua para fins domésticos ou profissionais foi uma prática proibida, porque as zonas públicas circundantes às habitações costumavam estar ocupadas, sujando e impossibilitando a circulação nas ruas, como constatamos nos costumes e foros de Alfaiates $^{28}$, de Castelo Rodrigo ${ }^{29}$, de Castelo Melhor ${ }^{30}$, de Santarém ${ }^{31}$, de Borba e de Beja ${ }^{32}$. Também, os maus cheiros e os

${ }^{26}$ BRANDÃO, Zeferino Brandão. Monumentos e Lendas de Santarém. Lisboa: David Corazzi Editor, 1883, pág. 410, Tít. [236].

${ }^{27}$ Embora estejamos a usar um conceito contemporâneo e anacrónico, conseguimos através dos costumes e foros detetar uma clara consciência das comunidades medievais dos riscos e incómodos que determinados mesteres podiam causar. O desenvolvimento destes ofícios dependia de fornos de transformação que implicavam o uso do carvão e do fogo, contribuindo para a proliferação de incêndios, fazendo perigar as populações e os seus bens. Salientamos que estas profissões deixavam rastos de sujidade e resíduos nas ruas, colocando em causa a higiene e a salubridade. Veja-se: MARTÍNEZ Y MARTÍNEZ, Julio. "El delito ecológico en los Fueros de Coria y Cáceres". (Un estudio Iushistórico Textual-Comparativo). Cáceres: JGMM Zigurat Libros, 1994-2001.

28 "CFA", Portvgaliae Monumenta Historica. Leges et Consuetudines. vol. I. Olisipone: IUSSU Academiae Seicentiarum Olisiponensis, MDCCCLVI, 1856, p. 809, Tít. [162].

29 "CFCR", Portvgaliae Monumenta Historica. Leges et Consuetudines. vol. I. Olisipone: IUSSU Academiae Seicentiarum Olisiponensis, MDCCCLVI, 1856, p. 869,Tít. [170].

30 "CFCM", Portvgaliae Monumenta Historica. Leges et Consuetudines. vol. I. Olisipone: IUSSU Academiae Seicentiarum Olisiponensis, MDCCCLVI, 1856, p. 915, Tít. [158].

31 "CFS", Portvgaliae Monumenta Historica. Leges et Consuetudines. vol. II. Olisipone: IUSSU Academiae Seicentiarum Olisiponensis, MDCCCLVI, 1856, p. 28, Tít. [119]; BRANDÃO. Zeferino. Monumentos e Lendas de Santarém. Lisboa: David Corazzi - Editor, 1883, p. 388-389, Tít. [140]. 
resíduos acumulados, resultantes destes mesteres, bem como do armazenamento de feno e de palha no interior das casas ${ }^{33}$, podiam ser nocivos para o bem-estar das pessoas, sendo causadores de quezílias entre os habitantes. Daí, a necessidade de afastar tudo aquilo que pudesse ser prejudicial para as populações, zelando pela manutenção da paz e da saúde pública.

\section{A rua e as atividades económicas}

Complementemos a nossa análise com mais uma faceta das ruas, a sua vertente económica. Estes espaços públicos eram importantes para o desenvolvimento da economia dos concelhos, pois possibilitavam o desenvolvimento das atividades mesteirais e comerciais. As vias públicas eram, portanto, espaços de trabalho, funcionando como um prolongamento das próprias casas e das oficinas dos mesteirais, que normalmente se localizavam no piso térreo. Por outro lado, as ruas podiam também ser entendidas como uma espécie de escaparate de produtos, onde eram expostos para os transeuntes ver e poder negociar. $\mathrm{O}$ desenvolvimento das atividades dos mesteirais nem sempre decorria de forma pacífica, detetando uma série de conflitos na documentação costumeira objeto de estudo. Temos, assim, o exemplo dos viandantes que passavam pelas ruas, interrompendo a circulação de pessoas e de mercadorias, como acontecia nas vilas ribacoanas de Castelo Rodrigo e Castelo Melhor, a propósito das fiandeiras que tinham o hábito de fiar nas ruas para fins profissionais ou domésticos ${ }^{34}$.

Pelas ruas, circulavam comerciantes, padeiras, almocreves, mercadores e outros agentes comerciais que aproveitam as suas deslocações para vender os seus produtos e se dirigirem para outros espaços, reservados ao comércio, tais como mercados, fangas, açougues e entre outros. Todos estes profissionais, tais como os mesteirais encontravam-se regulamentados, dispondo de um conjunto de normas específicas sobre as suas atividades, designadas de coutos do concelho (GONZÁLEZ ARCE, 1995, p. 88), isto é, padrões "industriais" e comerciais, que lhes conferiam uma identidade

32 "CFB", Portvgaliae Monumenta Historica. Leges et Consuetudines. vol. II. Olisipone: IUSSU Academiae Seicentiarum Olisiponensis, MDCCCLVI, 1856, p. 69, Tít. [206].

33 "CFA", Portvgaliae Monumenta Historica. Leges et Consuetudines. vol. I. Olisipone: IUSSU Academiae Seicentiarum Olisiponensis, MDCCCLVI, 1856, p. 808 e 847, Títs. [159], [530] e [531].

34 "CFCM", Portvgaliae Monumenta Historica. Leges et Consuetudines. vol. I. Olisipone: IUSSU Academiae Seicentiarum Olisiponensis, MDCCCLVI, 1856, p. 915, Tít. [158], Lv. IV; CFCR", Portvgaliae Monumenta Historica. Leges et Consuetudines. vol. I. Olisipone: IUSSU Academiae Seicentiarum Olisiponensis, MDCCCLVI, 1856, p. 170, Tít. [869], Lv. IV. 
própria. Estas tinham o objetivo de controlar as etapas da produção, o comércio e o abastecimento das cidades; definir os preços (da mão de obra e dos produtos finais no mercado), as medidas e os pesos usados nas transações, proporcionando-lhes produtos de boa qualidade e a preços acessíveis. Apesar disso, estes coutos dos concelhos, nem sempre tiveram os efeitos desejados, como podemos constatar na presença de várias rúbricas, quando examinamos os regulamentos costumeiros. Salientamos, a modo de exemplo, o caso das padeiras. Estas costumavam vender pão mal cozido, impróprio para consumo. Diante destas circunstâncias, os compradores de Riba-Côa eram obrigados a devolver os pães previamente cortados para ser testada a qualidade, ficando as padeiras obrigadas a recebê-los de volta e, além disso, deviam ser multadas ${ }^{35}$.

Os regateiros eram outros comerciantes que faziam das ruas palcos dos seus negócios. Estes eram agentes intermediários que se dedicavam ao comércio a retalho de quaisquer produtos, se bem que eram mal vistos, como nos deixam transparecer os costumes e foros. Este facto está relacionado com os enganos que eram praticados contra os consumidores e também com a tendência a monopolizar as mercadorias para depois as venderem a preços elevados, prejudicando assim o abastecimento normal dos habitantes dos concelhos, ao mesmo tempo, que os lesavam no acesso ao consumo. Desta forma, os regateiros podiam obter lucros facilmente e de forma ilegítima, em detrimento das populações. Assim, acontecia na vila de Santarém, a propósito do comércio do pão levado a cabo pelas regateiras. Estas tinham o costume de comprar pães às padeiras para o revenderem, especulando o preço deste produto, consoante a demanda. ${ }^{36}$ Este caso era semelhante em Riba-Côa, mas, em relação ao peixe, levando as autoridades locais a regulamentar o seu comércio $^{37}$. O consumo deste alimento era motivo de conflitos, uma vez que consistia na base da alimentação quer dos cristãos nos

\footnotetext{
35 "CFCB", Portvgaliae Monumenta Historica. Leges et Consuetudines. vol. I. Olisipone: IUSSU Academiae Seicentiarum Olisiponensis, MDCCCLVI, 1856, p. 763, Tít. [157]; "CFCM", Portvgaliae Monumenta Historica. Leges et Consuetudines. vol. I. Olisipone: IUSSU Academiae Seicentiarum Olisiponensis, MDCCCLVI, 1856, p. 925, Tít. [249], Lv. VI; "CFCR", Portvgaliae Monumenta Historica. Leges et Consuetudines. vol. I. Olisipone: IUSSU Academiae Seicentiarum Olisiponensis, MDCCCLVI, 1856, p. 881, Tít. [262], Lv. VI; "CFA”, Portvgaliae Monumenta Historica. Leges et Consuetudines. vol. I. Olisipone: IUSSU Academiae Seicentiarum Olisiponensis, MDCCCLVI, 1856, p. 808, Tít. [157].

36 BRANDÃO. Zeferino Brandão. Monumentos e Lendas de Santarém. Lisboa: David Corazzi Editor, 1883, p. 407 - 408, Tít. [228].

37 "CFCB", Portvgaliae Monumenta Historica. Leges et Consuetudines. vol. I. Olisipone: IUSSU Academiae Seicentiarum Olisiponensis, MDCCCLVI, 1856, p. 772, Tít. [236]; "CFCM”, Portvgaliae Monumenta Historica. Leges et Consuetudines. vol. I. Olisipone: IUSSU Academiae Seicentiarum Olisiponensis, MDCCCLVI, 1856, p. 921, Tít. [237], Lv. VI; "CFCR”, Portvgaliae Monumenta Historica. Leges et Consuetudines. vol. I. Olisipone: IUSSU Academiae Seicentiarum Olisiponensis, MDCCCLVI, 1856, p. 880, Tít. [250], Lv. VI.
} 
dias de abstinência, quer dos judeus para a celebração do "Shabat", que se iniciava ao fim do dia de sexta-feira e terminava no fim do dia de Sábado. (BRAGA, 2015, p. 4344). Os regateiros, os vendedores e os judeus aproveitavam-se destas oportunidades para comprar, açambarcar e revender os peixes, contribuindo para o seu encarecimento $^{38}$. A este cenário, podemos ainda acrescentar uma interpretação socioreligiosa relacionada com o contato e a manipulação dos alimentos por pessoas judias ou cristãs (CANTERA MONTENEGRO, 2003, p. 43), levando os concelhos e estabelecer normas que restringissem as relações comerciais e sociais entre ambos os grupos, que nem sempre seriam eficazes.

Através destas fontes jurídicas ficamos a saber que medir e pesar mal as mercadorias era uma prática recorrente que procurava ser colmatada. Temos, portanto, indicações de que, em Riba-Côa, se utilizavam diversos estratagemas, tais como as medidas e os pesos falsos, estrangeiros ${ }^{39}$ (provenientes de outros locais) ou viciados para prejudicar os consumidores nas trocas comerciais. Para minimizar estas situações, os concelhos apostaram na aplicação de multas e na vigilância levada a cabo por funcionários municipais especializados, como os «ochaveiros»e os almotacés, com as funções de regular e superintender os pesos, as medidas, os preços e os tributos. Posto isto, recaía nos concelhos a responsabilidade de controlar o desenvolvimento das atividades económicas, mediante os referidos coutos dos concelhos. Todos os mesteirais e agentes comerciais ficavam obrigados a obedecer aos padrões do concelho, chegando ao ponto de disporem de normativas específicas para cada atividade. Cada mesteiral ganhava, portanto, uma identidade própria, “[...] reconociéndosele un valor y utilidad para la comunidad" (GONZÁLEZ ARCE, 1995, p. 88). O que se pretendia, como acabamos de enunciar, consistia em assegurar o bom funcionamento das cidades, controlar a economia local e proporcionar produtos de boa qualidade aos consumidores, em função dos preços estabelecidos.

\footnotetext{
38 "CFCM", Portvgaliae Monumenta Historica. Leges et Consuetudines. vol. I. Olisipone: IUSSU Academiae Seicentiarum Olisiponensis, MDCCCLVI, 1856, p. 924, Tít. [239], Lv. VI; "CFCR", Portvgaliae Monumenta Historica. Leges et Consuetudines. vol. I. Olisipone: IUSSU Academiae Seicentiarum Olisiponensis, MDCCCLVI, 1856, p. 880, Tít. [252], Lv. VI.

39 "CFA", Portvgaliae Monumenta Historica. Leges et Consuetudines. vol. I. Olisipone: IUSSU Academiae Seicentiarum Olisiponensis, MDCCCLVI, 1856, p. 824, Tít. [300].
} 


\section{Conclusão}

Em suma, e seguindo a linha de pensamento de Chueca Goitia (1996, p. 7) a propósito da cidade, estudar a rua pressupõe, de igual forma, um desafio, uma vez que estamos diante de uma temática bastante ampla, que pode ser tratada a partir de diversos pontos de vista, exigindo-nos um trabalho transdisciplinar e sistemático que englobe, sobretudo a história, o direito, a linguística, entre outras áreas do conhecimento. Neste sentido, escolhemos a rua para pilar deste estudo. Com base numa única fonte de caráter jurídico - os costumes e foros -, centramos a atenção nas vivências quotidianas das populações concelhias mediévicas portuguesas. Em poucas palavras e, para simplificar, partimos de três categorias completamente diferentes: a criminalidade urbana; a higiene e a salubridade e, por fim, as práticas económicas, mesteiral e comercial, que se desenvolviam nas ruas.

A escolha dos costumes e foros deve-se a várias razões, entre as quais, salientamos a melhor compreensão, por um lado, dos crimes levados a cabo nas ruas e, por outro lado, permite-nos refletir sobre as molduras penais e as medidas preventivas estabelecidas pelos concelhos. Ao compulsarmos os regulamentos costumeiros, podemos afirmar que as autoridades locais procuraram respostas e soluções para os comportamentos de violência, de delinquência e os conflitos quotidianos nos centros urbanos medievais. Não obstante, somos também levados a pensar que nem sempre as normativas terão surtido efeito, visto que conseguimos detetar várias rúbricas a chamar a atenção para os mesmos crimes e as mesmas transgressões urbanas. A fonte selecionada possibilita-nos, acima de tudo, o conhecimento da organização das cidades, proporcionando-nos uma vasta panóplia de oportunidades de estudo, tais como as ruas, objeto de análise ao longo deste texto.

Neste sentido, as ruas eram espaços com múltiplas funções. Eram cenários de criminalidade, conflitos e violências urbanas; de negócios e transações mercantis; depósitos de lixos e resíduos; de proliferação de doenças. Neste sentido, as ruas eram, acima de tudo, um prolongamento dos espaços domésticos, levando as pessoas a desempenharem os seus ofícios e as suas atividades, sem olharem a quaisquer preocupações urbanas e ao bem-estar dos moradores. Por outro lado, assistimos a um despontar de um interesse estético que ia além da utilidade prática destes espaços públicos, necessitando de organização, de manutenção e de limpeza, incumbindo a responsabilidade aos habitantes dos concelhos. Ao cotejarmos as normativas 
costumeiras, encontramos assim um conjunto de medidas com estes propósitos, com o objetivo de dar resposta aos problemas e conflitos que pudessem advir do dia-a-dia nas ruas. Embora, nem sempre terão sido eficazes. 
Siglas:

CFA - Costumes e Foros de Alfaiates

CFB - Costumes e Foros de Beja

$\mathrm{CFBb}$ - Costumes e Foros de Borba

CFCB - Costumes e Foros de Castelo Bom

CFCM - Costumes e Foros de Castelo Melhor

CFCR - Costumes e Foros de Castelo Rodrigo

CFS - Costumes e Foros de Santarém

CFTN - Costumes e Foros de Torres Novas

CSCVNA - Costumes de Santarém comunicados a Villa Nova d'Alvito

Liv. - Livro

Tít. - Título

\section{REFERÊNCIAS}

\section{Fonte primária}

BRANDÃO, Zeferino. Monumentos e Lendas de Santarém. Lisboa: David Corazzi Editor, 1883.

Portvgaliae Monumenta Historica. Leges et Consuetudines. vol. I e II. Olisipone: IUSSU Academiae Seicentiarum Olisiponensis, MDCCCLVI, 1856.

RODRIGUES, Maria Celeste Matias. Dos Costumes de Santarém. 1992. (Mestrado em Linguística Portuguesa Histórica - A Faculdade de Letras da Universidade de Lisboa, Lisboa, 1992.

\section{Fonte Secundária}

ÁLVAREZ FERNÁNDEZ, María. Urbanismo medieval asturiano a fines de la Edad Media. Financiación y gestión del espacio público, entre la tradición medieval y la modernidad (Oviedo, Siglos XV-XVI). In: RIBEIRO, Maria do Carmo; MELO, Arnaldo Sousa (Org.). Evolução da Paisagem Urbana. Transformação morfológica dos tecidos históricos. Porto: Centro de Investigação Transdisciplinar Cultura, Espaço e Memória; Instituto de Estudos Medievais, 2013. p. 141-165.

BAZÁN DÍAZ, Iñaki. La violencia legal del sistema penal medieval ejercida contra las mujeres. Clio \& Crimen. Revista del Centro de Historia del Crimen de Durango, Durango, n. 5, p. 203-227, 2008. Disponível em: <http://www.durangoudala.net/portalDurango/RecursosWeb/DOCUMENTOS/1/0_525_1.pdf >. Acesso em: 12 jan. 2012. 
BEIRANTE, Maria Ângela V. da Rocha. Santarém Medieval. Lisboa: Universidade Nova de Lisboa e Faculdade de Ciências Sociais e Humanas, 1980.

BEIRANTE, Maria Ângela V. Évora na Idade Média. Lisboa: Fundação Calouste Gulbenkian e Junta Nacional de Investigação Científica e Tecnológica, 1995.

BERNAL PEÑA, José. Golfines y asesinos. Elementos y motivaciones de las conductas violentas en Murcia durante el siglo XIV. MVRGETANA, Murcia, n. 35, p. 27-50, 2011.

BONACHÍA HERNANDO, Juan A. La ciudad en las Partidas: edificaciones y apostura urbana. In: RIBEIRO, Maria do Carmo; MELO, Arnaldo Sousa (Org.). Evolução da Paisagem Urbana. Transformação morfológica dos tecidos históricos. Porto: Centro de Investigação Transdisciplinar Cultura, Espaço e Memória; Instituto de Estudos Medievais, 2013. p. 91-117.

BRAGA, Isabel Drumond. Carne e peixe: uma hierarquia de consumos alimentares. In: BRAGA, Isabel Drumond; BRAGA, Paulo Drumond (Org.). Animais e Companhia na História de Portugal. Lisboa: Círculo de Leitores, 2015. p. 43-44.

BUENO DOMÍNGUEZ, María Luísa. Contactos con la vida material en Zamora. Siglos XIIXV. Espacio, Tiempo y Forma (Serie III, H $H^{a}$ Medieval), Madrid, v. 18, p. 39-58, 2015.

CANTERA MONTENEGRO, Enrique. La carne y el pescado en el sistema alimentario judío en la España Medieval. Espacio, Tiempo y Forma (Serie III, $\mathrm{H}^{\mathrm{a}}$ Medieval), Madrid, n. 16, p. 13-51, 2003. Disponível em: <http://espacio.uned.es/fez/eserv.php?pid=bibliuned:ETF366B37E9-B682-D954-BEFD-

7F1F77C2556E\&dsID=PDF>. Acesso em: 12 fev. 2011.

CARDOSO, Isabel Vaz de Freitas Botelho. Recolher obrigatório: uma imposição da noite medieval. Revista de Ciências Históricas, Porto, v. 13, p. 31-41, 1998.

CHUECA GOITIA, Fernando. Breve História do Urbanismo. Lisboa: Editorial Presença, 1996.

CINTRA, Luís Filipe Lindley. A linguagem dos Foros de Castelo Rodrigo e seu confronto com a dos Foros de Alfaiates, Castelo Bom, castelo Melhor, Coria, Cáceres e Usagre. Contribuição para o estudo do leonês e do galego-português do século XIII. Lisboa: Instituto Nacional Casa da Moeda, 1984.

CÓRDOBA LA LLAVE, Ricardo. El homicidio en Andalucía a fines de la Edad Media. Primera Parte. Estudio. Clio \& Crimen. Revista del Centro de Historia del Crimen de Durango. (La represión de la disidencia religiosa: de la Inquisición Medieval a la Moderna), Durango, n. 2, p. 281-504, 2005. Disponível em: <http://www.durangoudala.net/portalDurango/RecursosWeb/DOCUMENTOS/1/0_455_1.pdf>. Acesso em: 3 jun. 2007.

CÓRDOBA LA LLAVE, Ricardo. Consideraciones en torno al delito de agresión sexual en la Edad Media. Clio \& Crimen. Revista del Centro de Historia del Crimen de Durango, Durango, n. 5, p. 187-202, 2005. Disponível em: <http://www.durangoudala.net/portalDurango/RecursosWeb/DOCUMENTOS/1/0_524_1.pdf>. Acesso em: 12 jun. 2012. 
DOMINGUES, José; PINTO, Pedro. Os foros extensos na Idade Média em Portugal. Revista de Estudios Histórico-Jurídicos, Valparaíso, n. 37, p. 153-174, 2015.

SILVA, Ferreira e. Notas para uma sociologia do direito. Lisboa: Livraria Morais, 1962.

GONZÁLEZ ARCE, José Damián. El artesanado en los Fueros del Reino de Murcia. Anuario de Estudios Medievales, Madrid, n. 25, p. 81-126, 1995.

GONÇALVES, Iria. Posturas municipais e vida urbana na Baixa Idade Média: o exemplo de Lisboa. In: GONÇALVES, Iria (Org.). Um olhar sobre a cidade medieval. Cascais: Patrimonia Histórica, 1996. p. 77-95.

HINOJOSA, Eduardo. Eı Elemento Germánico en el Derecho Español. Madrid: Junta para ampliación de Estudios e investigaciones científicas. Centro de Estudios Históricos, 1915.

LADERO QUESADA, Manuel Fernando. La vivienda. Espacio público y espacio privado en el paisaje urbano medieval. In: IGLEISA DUARTE, José Ignacio de la (Org.). En La vida cotidiana en la Edad Media. VIII Semana de Estudios Medievales. Nájera: Instituto de Estudios Riojanos, 1998, p. 111-128. Disponível em: $<$ https://dialnet.unirioja.es/servlet/articulo?codigo=563903>. Acesso em: 28 maio 2012.

LÓPEZ VILLALBA, José Miguel. Política local y abastecimiento urbano: el pescado en Guadalajara en la Baja Edad Media. Studia Historica. Historia Medieval, Salamanca, n. 25, p. 221-244, 2007.

MARTÍNEZ MARTÍNEZ, Julio Gerardo. Los oficios menestrales en los Fueros de Cáceres. Anuario de la Facultad de Derecho, Cáceres, n. 3, p. 133-165, 1984-1985.

MARTÍNEZ MARTÍNEZ, Julio Gerardo. "El delito ecológico en los Fueros de Coria y Cáceres”. (Un estudio Iushistórico Textual-Comparativo). Cáceres: JGMM Zigurat Libros, 1994-2001.

MONTERDE GARCÍA, Juan Carlos. El sentido de la honra en los Fueros de Cáceres y Plasencia. Revista de Estudios Extremeños, Badajoz, v. 58, n. 2, p. 685-722, 2002. Disponível em: <http://dialnet.uinirioja.es/servlet/revista?tipo_busqueda=CODIGO\& clave_revista=1164>. Acesso em: 22 de maio 2007.

ORLANDIS, José. Las consecuencias del delito en el derecho de la Alta Edad Media. Anuario de Historia del Derecho de Español, Madrid, n. 18, p. 61-165, 1947.

PAIS, José Machado. Sociologia da vida quotidiana. Teorias, métodos e estudos de caso. Lisboa: Imprensa Nacional de Ciências Sociais, 2002.

SAINZ GUERRA, Juan. Infracción y pena en el Fuero de Soria. Anuario de Historia del Derecho de Español, Madrid, n. 76, p. 137-170, 2006.

SEABRA, Ana Maria Rodrigues. Espaços, gente e sociedade no Oeste: estudos sobre Torres Vedras. Cascais: Patrimónia Histórica, 1996. 
SILVA, Manuela Santos. Óbidos medieval: estruturas urbanas e administração concelhia. Cascais: Patrimónia Histórica, 1997.

SILVA, Manuela Santos. O concelho de Óbidos na Idade Média. Caldas da Rainha: Gráfica da Ponte, 1994.

SILVA, Nuno Espinosa Gomes da. História do Direito Português. Lisboa: Associação Académica da Faculdade de Direito, 1971. 